\title{
Development of Self Repairable Concrete System
}

\author{
Sahebrao.G.Kadam, Dr. M.A.Chakrabarti \\ (Department of structural engineering, VJTI, Mumbai, India)
}

\begin{abstract}
During the serviceability of structure concrete is subjected to different damages. The common approach for repair of Structural concrete are: Polymer Injunction, External prestressing, Geomembranes and Polymer wraps. The above technique is based on addition of a repair material to concrete from outside to inside of structural members. Now we are going to develop the self-repairing concrete by adding the materials from inside the concrete to repair.

Our technique to develop self-repairing concrete consists of embedding repairing materials in hollow ducts in the repairing zone before it is subjected to damage. Therefore when cracks occurs this repairs materials will get released from inside and it will enter the repairing zone. Where it will penetrate into cracks and rebound to mother material of Structure and it will repair the damage.
\end{abstract}

Keywords: - Concrete - Serviceability - Cracks - Epoxy resins - Repairs.

\section{INTRODUCTION}

In Structural Engineering concrete is basic

material used in R.C.C \& Prestressed concrete. Our technique is to develop self-repairing concrete consists of embedding repairing materials in hollow ducts in the repairing zone before it is subjected to damage or crack. Therefore when cracks occurs this repairs materials will released from inside duct and it will enter the repairing zone. Where it will penetrate into cracks and rebound to mother material of structure. The cracking and damages are associated with low tensile strain capacity of concrete, get repaired with our chemical present inside. Thus we repair the problem where it occurs and just in time automatically without material intervention. Long term durability can be achieved by dimensional stability which means less stress from thermal contraction, autogenously shrinkage and drying shrinkage. Hence technique we utilized does precisely that it adds more materials to the concrete repair zone from inside upon demand when it is triggered by events such as cracking. Our approach consists to address the bonding problem of repair material from inside the concrete therefore definitely better technique compared to other methods. It is seen that self-repairing performs better because the resin is flexible itself and keep on releasing the each brittle failure that is cracks. The ability to fill in for dimensional gaps has been shown to work with self- repairing resins that grow larger in volume. The internal released stiff resins are less brittle, more ductile and stronger in tension as compare to concrete. This type of technique is useful for structural member subjected to bending, shear cracks, etc. This approach of self-repairing is useful for bridges having pre-stressed box girders where dynamics, moving loads cyclic loads are in huge quantity and development of minor to major cracks possibility is more.

Hence our approach consist of embedding repair material in hollow ducts in cracking or tension zone before it subjected to damage. Therefore when cracking occurs, this repair material is released from inside the brittle tubes and enters in damage zone/area, where it penetrates into cracks and

rebounds to the mother material of structure and

structure being repair.

\section{BACKGROUND OF THE RESEARCH}

In literature survey last 20 years different research has develop the self-repairing techniques in different country under different climatic conditions, assumptions, and materials, etc. Out of which Dr. Carolyn Dry from USA has developed the practical technique of Development of self-repairing durable concrete [1]. In his work investigation was made into development of transparent polymer matrix composites that have the ability to self-repair internal cracks due to Mechanical loading. In his work focused on cracking of hollow Repair fibers disposed in a matrix and subsequent release of repair chemicals in order to visually assess the repair and speed of repairs in the impact test the polymer specimen was released in ten seconds. Similarly, Mihashi and Yoshio proposed incorporating glass pipes containing the repairing agent into the concrete for self-healing capabilities to restore strength and for the prevention of water leakage [2]. This concept was also utilized by $\mathrm{Li}$ et al. who incorporated hollow glass fibers containing ethyl cyanoacrylate, a thermoplastic monomer, into the mix [3]. This filled hollow-fiber method has been successful in other concrete systems as well as reinforced polymers and epoxies [4-10], but limitations such as a lack of ease 
in manufacturing have made these products undesirable for commercial use.

Sottos et al. have developed a polymer composite system that incorporates a catalyst into the polymer matrix phase with a microencapsulated repair agent [11]. The healing agent is released upon crack propagation through the microcapsule, resulting in as much as an $80 \%$ recovery of toughness after a fracture. This method has been successfully demonstrated in various polymer composite systems [12-14].

\section{PROPERTIES OF MATERIAL}

In development of self-repairable concrete system main component i.e. resin and hardener were selected such that, it will get mixed together after formation of crack and will get set within crack with addition of sealing it. Some criteria for the selection of resin considered are,

a) The material should be able to repair different types and sizes of damages.

b) It should be economically viable.

c) It should be easily available in market.

d) While using the chemical it should not cause hazardous effects.

e) It should establish good quality assurance and reduce life cycle cost.

f) It should withstand different forces and dynamic loads.

g) It should have satisfactory properties like compressive strength, viscosity and $\mathrm{pH}$. $\mathrm{pH}$ value is such that it will not cause any corrosion to the reinforcement. Viscosity of both the chemical shall be such that it will seal the minor cracks like shrinkage or temperature cracks. Working temperature of both the solution shall be wide. Void former of polyurethane selected so that it can be easily removed from concrete specimen as there is no friction between surfaces. This void former material is elastic and easily available in various diameters.

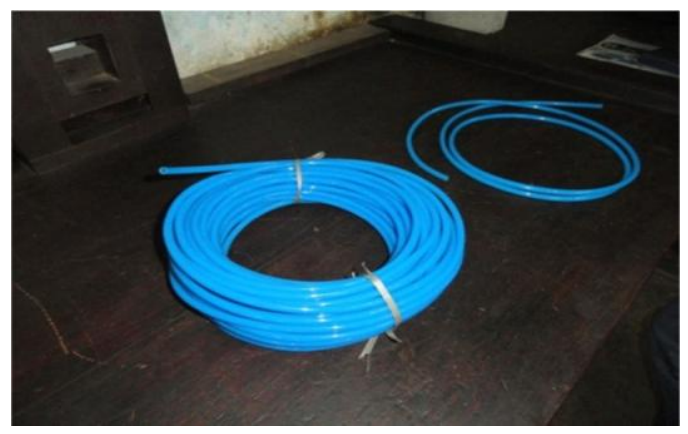

Void Former (Polyurethane Material)

Fig. 1

\subsection{Research Methodology}

The methodology is mainly designed for flexural member and for crack formation within that member due different loadings. To carry out one point flexural test a concrete specimen of $300 \mathrm{~mm} x$

$70 \mathrm{~mm} \times 1000 \mathrm{~mm}$ with $6 \mathrm{~mm}$ dia. mild steel bars is such selected do that it will be a flexural member with sufficient width so that matrix of hollow ducts can be laid along it on the tension side of section. In the initial stage of testing we have provided ducts along the length of member with the help of polyurethane material of $6 \mathrm{~mm}$ diameter. This Ducts then alternately filled with epoxy solution and hardener.

Idea behind is when crack formation under loading will take place this two solutions will get mixed with each other forming hard compound together which will sealed the crack.

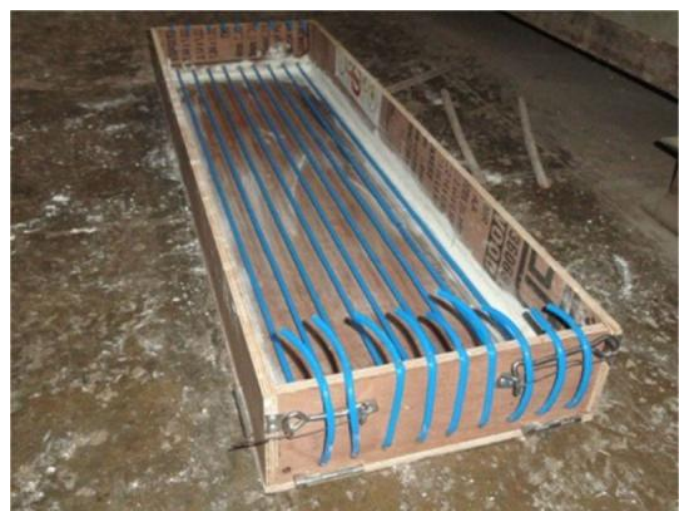

Arrangement of Void Former in Slab Fig. 2 


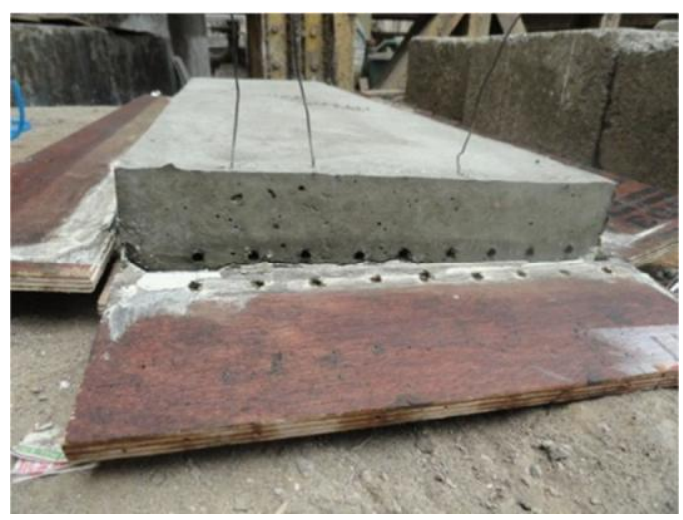

Slab specimen after removal of shutter with hollow duct to fill with resin Fig. 3

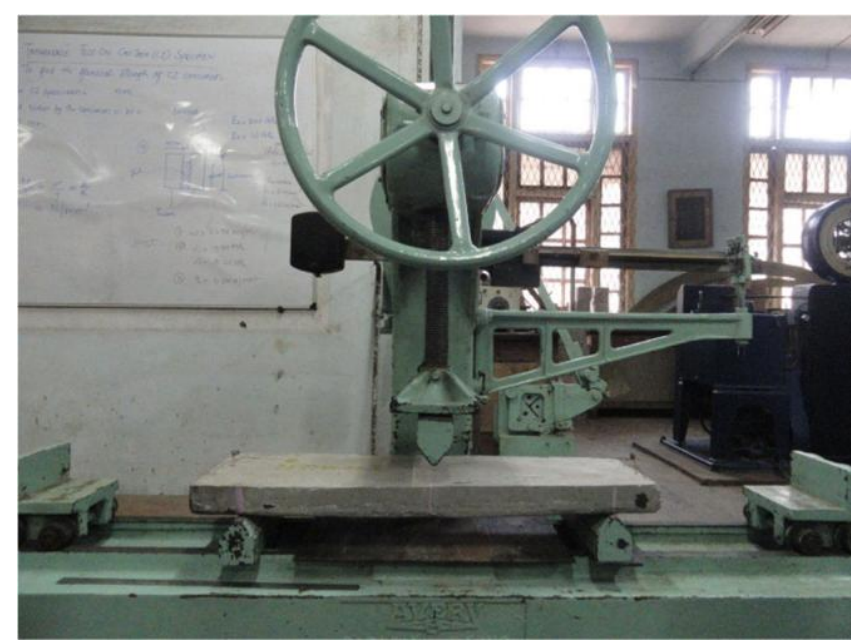

Slab specimen under one point flexural loading system (Ducts filled with resins) Fig. 4

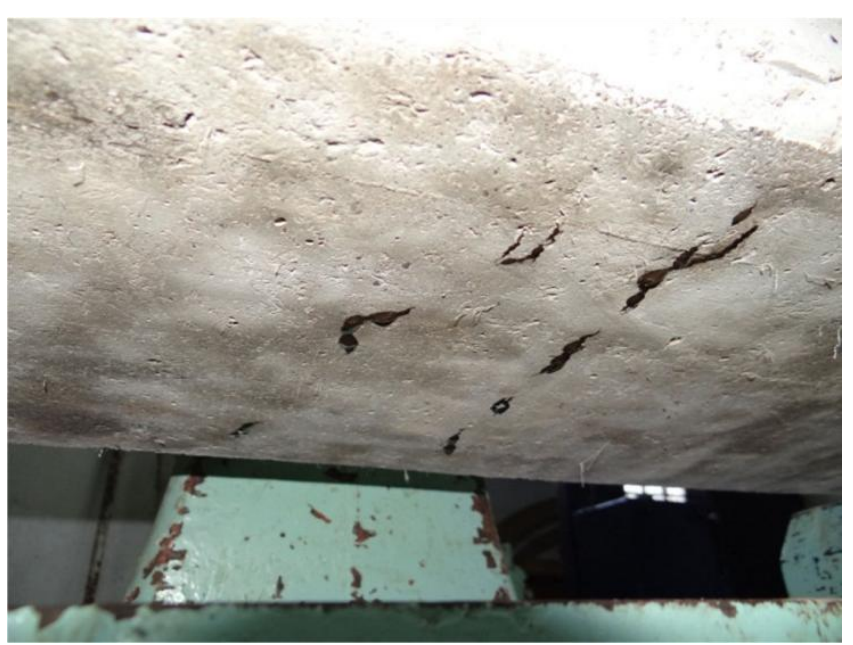

Soffit of slab after loading and crack formation Resin is released from voids through cracks Fig. 5 


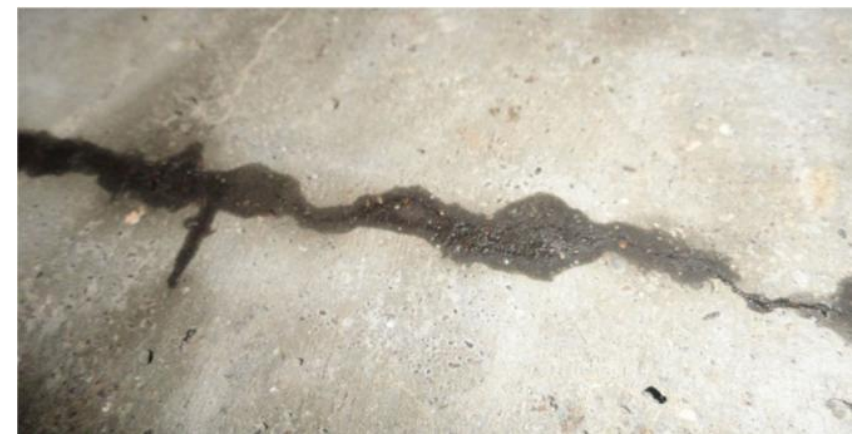

Soffit of slab after repair with chemical Cracks filled with resin

Fig. 6

\subsection{Results and Conclusion:}

One point flexural test was carried out on the specimen after 28 days of curing by feeling the resins. Load is gradually added till resin gets released through the cracks. Same test was again carried out after 7 days to ensure the curing with resins. Graph showing load vs. deflection of specimen.

\section{Load vs. Deflection}

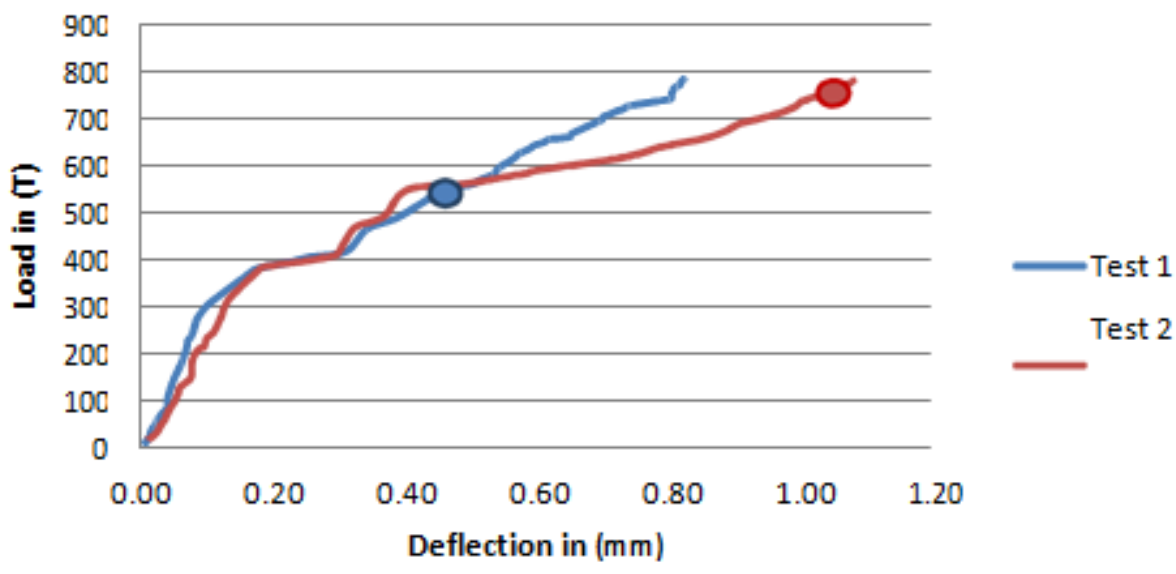

\section{IMPORTANT OBSERVATIONS}

- In case of first test chemical visible on surface for load of around $550 \mathrm{~kg}$ and in case of second test chemical getting released for load of around $750 \mathrm{~kg}$.

- Theoretical value of load for crack formation matches with the experimental value.

- Chemical is getting released through the cracks in desired way.

- Crack getting filled with the solution in proper manner.

- $\quad$ Crack getting sealed properly where there is proper mixing of resin and hardener.

- Amount of hardener and profile of ducts causes variation in reaction time of both solutions.

- $\quad$ As both solutions were kept separated, it will ensure automatic repairing system of concrete.

- After reaction of Resins and hardener the cemented material is formed equivalent to mother concrete. After air curing of said cemented material the strength of flexural member is increased more than $10 \%$, etc. Hence it is concluded that by this system allowing with the seal of crack strength of the member is also increased.

\section{REFERENCES}

[1] Dr. Carolyn Dry Has Carried Out Lot Of Work On Development Of Self Repairing Durable Concrete. Natural Process Design, Inc. Winona, Minnesota (507-452-9113).

[2] Mihashi, H. and Y. Kaneko, Intelligent concrete with self-healing capability. Transactions of the Materials Research Society of Japan, 2000. 25(2): p. 557-560.

[3] Li, V.C., Y.M. Lim, and Y.-W. Chan, Feasibility study of a passive smart self-healing cementitious composite. Composites Part B, 1998. 29B: p. 819-827.

[4] Pang, J.W.C. and I.P. Bond, A hollow fibre reinforced polymer composite ecompassing self- healing and enhanced damage visibility. composites Science and Technology, 2005. 65: p.1791-1799. 
[5] Dry, C.M., Alteration of matrix permeability and associated pore and crack structure by timed release of internal chemicals. Ceramic Transactions, 1991: p. 191-193.

[6] Dry, C.M., Passive tunable fibers matrices. International Journal of Modern Physics, 1992. 6: p. 2763-2771.

[7] Dry, C.M. Smart building materials which prevent damage or repair themselves. In Proceedings of the Materials Research Society Symposium. 1992. California: Materials Research Society.

[8] Dry, C.M. Smart materials which sense, activate and repair damage; hollow porous fibers in composites release chemicals from fibers for self- healing, damage prevention, and/or dynamic control. in First European conference on smart structures and materials. 1992. Glasgow, Scotland.

[9] Williams, G., R. Trask, and I.P. Bond, A self- healing carbon fibre reinforced polymer for aerospace applications. Composites Part A, 2007. 38(1525-1532).

[10] Williams, G., R. Trask, and I.P. Bond, Bioinspired self-healing of advanced composite strcutres using glass fibres. Journal of the Royal Society Interface, 2007. 4: p. 363-371.

[11] Sottos, N.R., M.R. Kessler, and S.R. White, Self- healing structural composite materials. Composites Part A: Applied Science and Manufacturing, 2004. 34(8): p. 743-753.

[12] Yin Tao, e.a., Self-healing woven glass fabric/epoxy composites with the healant consisting of micro-encapsulated epoxy and latent curing agent. Smart Material Structures, 2008. 17: p. 15-19.

[13] Brown, E.N., N.R. Sottos, and S.R. White,Retardation and repair of fatigue cracks in a microcapsule toughened epoxy composite- Part II: In situ self-healing Composites Science and Technology, 2005. 65(15-16): p. 2474-2480.

[14] Yin, T., et al., Self-healing epoxy composites- Preparation and effect of the healant consisting of microencapsulated epoxy and latent curing agent. Composites Science and Technology 2007. 67(2): p. 201-212. 